\title{
SCIDiC
}

International Journal of Dentistry and Oral Science (IJDOS)

ISSN: 2377-8075

\section{Effectiveness Of Lidocaine Gel Vs Lidocaine Spray As A Topical Anaesthetic Agent Before Inferior Alveolar Nerve Block}

Research Article

Prasanna Guru .E 1* $^{*}$ Abdul Wahab P.U ${ }^{2}$, Kathiravan Selvarasu³, Melvin George .A ${ }^{4}$

${ }^{1}$ Post Graduate Student, Department of Oral and Maxillofacial Surgery, Saveetha Institute of Medical and Technical Science, Saveetha University, Chennai 600077, India.

${ }^{2}$ Professor and Head, Department of Oral and Maxillofacial Surgery, Saveetha Dental College and Hospitals, Saveetha Institute of Medical and Technical Science, Saveetha University, Chennai 600077, India.

${ }^{3}$ Reader, Department of Oral and Maxillofacial Surgery, Saveetha Dental College and Hospitals, Saveetha Institute of Medical and Technical Science, Saveetha University, Chennai 600077, India.

${ }^{4}$ Senior Lecturer, Department of Oral and Maxillofacial Surgery, Saveetha Dental College and Hospitals, Saveetha Institute of Medical and Technical Science, Saveetha University, Chennai 600077, India.

\section{Abstract}

Background: Inferior alveolar nerve block (IANB) is the most common, painful, and anxiety-provoking procedure involving needle insertion for anaesthetic solution deposition. Though various methods have been introduced to reduce pain during dental procedures, still to perform pain control during the administration of local anaesthesia injection is the commonest modalityduring dental procedures

Aim: The aim of this study was to evaluate and compare the effectiveness of lidocaine gel and lignocaine hydrochloride $2 \%$ spray in pain reduction during IANB.

Materials and Methods: 30 healthy patients,[Male-15,Female-15] aged 20 to 60 years old, who required administration of local anaesthetics in the pterygomandibular area for their dental treatment. Pain responses were compared based on subject self report using visual analogue scale (VAS).Duration of onset of action for the 3 groups were recorded.

Results: Lidocaine spray is more effective than lidocaine gel as a topical anaesthetic agent.There is not much difference after a waiting period of 1 minute or 3 minutes.

Conclusion: Patients experienced less pain during the time of injection prick on application of Lidocaine spray than on application of lidocaine gel. Hence for Inferior Alveolar Nerve block application of EMLA topically before injection prick to avoid pain and discomfort to the patient,so that patient experiences a painless dental procedure.

Keywords: Topical Anaesthestics; Lidocaine Spray; Lidocaine Gel; Pain; Visual Analog Scale; Inferior Alveolar Nerve Block.

\section{Introduction}

Local anaesthesia is used to control pain during several dental procedures. Paradoxically, administration of local anaesthesia itself produce pain and anxiety that may cause subsequent unfavorable behaviour.Pain control is considered one of the most challenging aspects during IANB procedures. Although conduction anaesthesia and infiltration anaesthesia produce a deep anaesthesia, the use of needles may arouse fear and pain in patients. On the other hand, although the intensity of the anaesthesia is weak, topical anaesthetics with easy administration and reduces pain caused by needle injections and can thus generate positive responses towards dental treatment in patients. There are ongoing efforts to develop various forms of topical anaesthetics with more potent effects in order to facilitate the provision of quality care by dentists, upon a thorough understanding of the products. There has been much advancement in anaesthetic agents and techniques to achieve pain-free local anaesthesia. These include altering the $\mathrm{pH}$ or temperature of the anaesthetic solution and administering the injection at a low speed. Another effective method is to anesthetize the surface mucosa before needle insertion. The methods by which surface anaesthesia can be achieved include refrigeration, transcutaneous electric nerve stimulation, and topical anaesthesia.

\section{*Corresponding Author:}

Prasanna Guru .E,

Post Graduate Student, Department of Oral and Maxillofacial Surgery, Saveetha Institute of Medical and Technical Science, Saveetha University, Chennai 600077, India.

E-mail: prasanna.guru1996@gmail.com

Received: May 20, 2021

Accepted: August 5, 2021

Published: August 16, 2021

Citation: Prasanna Guru .E, Abdul Wahab P.U, Kathiravan Selvarasu, Melvin George .A. Effectiveness Of Lidocaine Gel Vs Lidocaine Spray As A Topical Anaesthetic Agent Before Inferior Alveolar Nerve Block. Int J Dentistry Oral Sci. 2021;8(8):3747-3750. doi: http://dx.doi.org/10.19070/2377-8075-21000768

Copyright: Prasanna Guru .E $\mathbf{E}^{\circ} 21$. This is an open-access article distributed under the terms of the Creative Commons Attribution License, which permits unrestricted use, distribution and reproduction in any medium, provided the original author and source are credited. 
For controlling the pain due to local anaesthetic injections, topical analgesia continues to be the most commonly used agent. The efficacy of topical anaesthetics depends on various factors such as the drug used, concentration, $\mathrm{pH}$, site of injection, additives, formulation and duration of application. Topical anaesthetics are commercially available as aerosols, ointments, gels, lozenges, tablets, pastes, powders, solutions and impregnated patches. The concentration of the agent varies depending on the formulation. Lignocaine spray and gel are two commonly used forms of topical anaesthetic agent.

Paucity of studies comparing the efficacy of these lidocaine spray and lidocaine gel prompted us to conduct this study which would enable the clinician to choose between an anaesthetic spray and gel, for use in Inferior Alveolar Nerve Block procedure. The purpose of our study was to evaluate and compare the efficacy of lignocaine in two different formulations in reducing pain caused by needle insertion during administration of local anaesthesia.

\section{Materials And Methods}

The present study was a split mouth experimental study, conducted in Saveetha Dental College and Hospital, Chennai from October 2020 to January 2021. A total of 30 patients [males (15), Females(15)] referred to the Department of Oral and Maxillofacial Surgery were recruited for the study.

An informed and written consent was taken before enrolment of study. The demographic and clinical parameters like age, gender, medical history,procedure of removal of tooth were identified and recorded in proforma.

\section{Inclusion Criteria}

Patientswho required bilateral IANB injections were included in the study.

\section{Exclusion criteria}

Patients who had co- morbid diseases like diabetes, renal failure, epileptic, cancer, endocarditis, immune compromised, pregnant women, patients who had prophylactic radiotherapy and who were extremely uncooperative were excluded from the study.

The thirty selected patients were divided into 3 groups of $10 \mathrm{pa}-$ tient each. Each group was assigned based on:

Group I: Were those in which in time interval was 30 seconds. Group II: Were those in which in time interval was 1 minute. Group III: Were those in which in time interval was 3 minutes.

The experiment was conducted by a single operator, who was trained to position the needle insertion. The participants were blind to the formulations applied as they were asked to close their eyes during application of topical anaesthesia. During the experi- ment, each participant was set in an upright position with the assistant holding the suction tip to prevent swallowing of any of the topical anaesthetics. Before topical anaesthesia application, the palatal mucosa was dried with a sterile gauze. $10 \%$ lidocaine spray or $2 \%$ lidocaine gel were applied randomly on either side, on the Pterygomandibular region .The first insertion was done using short needle gauge 26, at 30 seconds for Group I patients, 1 minute for Group II patients, after 3 minutes for Group III patients. The extraction procedure was carried after giving Inferior Alveolar Nerve Block concerning the tooth to be extracted. While extraction was carried if the patient felt any pain, it was recorded in the Visual analogue scale.The participant rated the degree of pain on the VAS.

\section{Assessment protocol}

All the patients were reviewed for complications in terms of pain during injection prick, duration for the onset of action of lidocaine spray and lidocaine gel.

\section{Pain}

Intensity of pain is measured by using Visual Analogue Scale (VAS) (McCormack et al., 1988) whereby the intensity of pain is divided into 10 scales with 0 indicates no pain at all and 10 as the most severe pain that the patient has ever suffered. Patients were asked to fill according to their experience on the respective evaluation days.

Each patient quantified the pain perceived during the injection using a 10-point visual analogue scale (VAS). The pain score for each of the patient was recorded.

\section{Duration of onset of action}

The duration of onset of action of local anaesthesia was measured using stop watch. Needle insertion was used to check the onset of anaesthesia. The onset of action for each patient was recorded.

\section{Statistical Analysis}

The sample size was calculated using the software G Power version 3.1.9.2. Paired t-Test was applied to compare mean values between time points and to analyse the mean values between the groups. We recorded the data of the patients and added to the database SPSS (IBM SPSS Statistics for Windows, Version 23.0, and Armonk, NY: IBM Corp. Released 2015). Significance level was set at $5 \%(p=0.05)$.

\section{Results}

A total of 15 males and 15 females patients with an average age of 22 years participated in the study. Among the teeth anesthetized, 37 were posterior and 4 were premolar teeth. No irritation

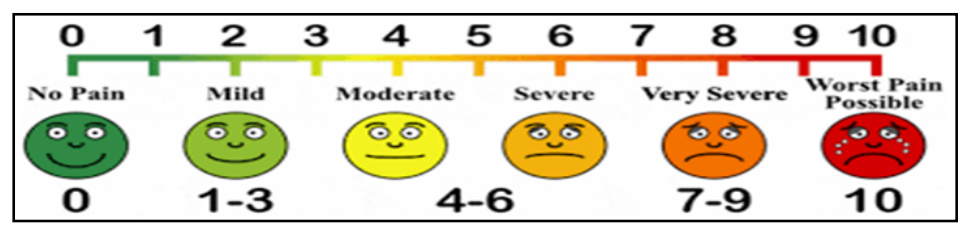


to mucosa or other adverse effects were reported. Paired t-test demonstrated that there was no significant difference in patient response (Visual Analogue Scale Pain Score) when either of the two agents were used $(p=0.07)$

A majority of the patients in groups I and II were males (52\% and $60 \%$, respectively). In group III, a majority of the patients werefemales $(60 \%)$. The gender distribution of the studied populationwas not significant $(\mathrm{p}=0.8139)$. The age of the studied population was in the range of $20-60$ years. On application of
Lignocaine spray, the VAS score was found to be reduced after 1 minute (1.6) and3 minutes (1.2). After 30 seconds, it was (2.64) (Fig. 1). The VAS score was found to be reduced with timeafter application of lignocaine gel. It was decreased from 3.48to 2.6 and 2.4 after 1 minute and 3 minutes, respectively (Fig. 2).In all the groups, VAS scores were higher in patients treated with Lignocaine gel as compared to Lignocaine spray. This difference wasfound to be statistically significant in all the groups according to thepaired t test (Table 1).

Figure 1. VAS score after application of Lignocaine spray.

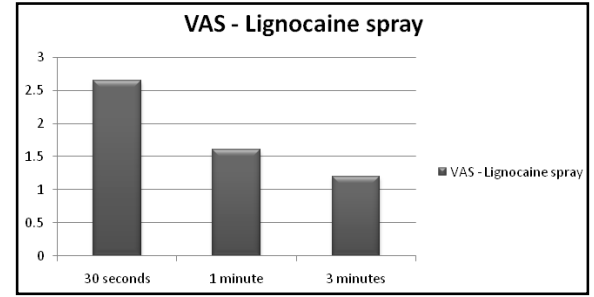

Figure 2. VAS score after application of Lignocaine gel.

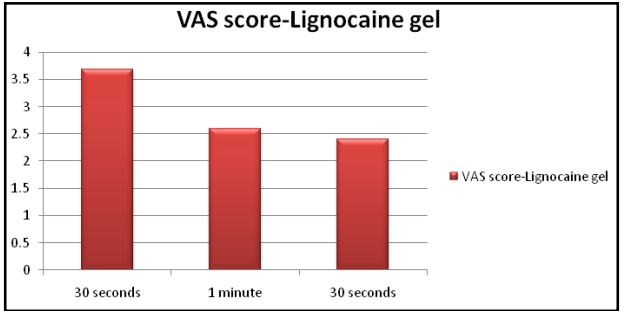

Table 1. Comparison of efficacy of Lignocaine spray and lignocaine gel (VAS scores).

\begin{tabular}{|c|c|c|c|}
\hline Paired t test (VAS score) & Group I & Group II & Group III \\
\hline $\mathrm{p}$-value & 0.0026 & 0.0341 & 0.0039 \\
\hline $\mathrm{p}<0.05$ & $\checkmark$ & $\checkmark$ & $\checkmark$ \\
\hline One- or two-tailed p-value & Two tailed & Two tailed & Two tailed \\
\hline
\end{tabular}

Figure 3. Application of Lignocaine spray on the pterygomandibular prior to local anaesthesia administration.

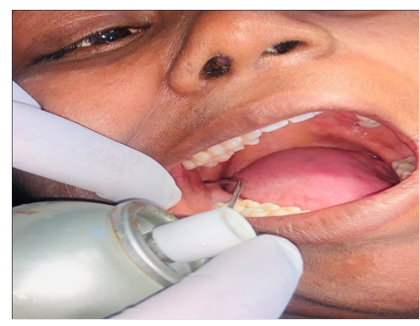

Figure 4. Application of lignocaine gel on the pterygomandibular prior to local anaesthesia administration.

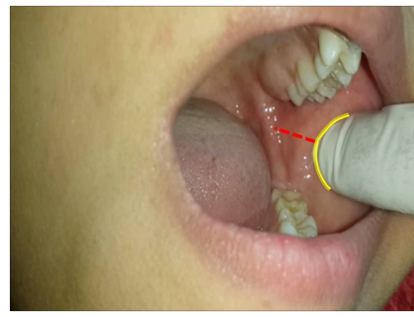

Figure 5. Needle insertion at 10 seconds, 1 minute and 3 minutes followed by Inferior Alveolar Nerve Block.

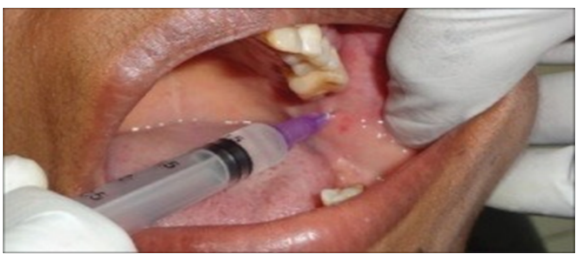




\section{Discussion}

Pain control is considered one of the most challenging aspects during IANB procedures. There has been much advancement in anaesthetic agents and techniques to achieve pain-free local anaesthesia. There is a considerable amount of information available concerning the efficacy and duration of local anaesthetics following intraoral injection. The efficacy and duration of intraoral anaesthesia varies between different local anaesthetic solutions and techniques. The duration of soft tissue anaesthesia varies between regional block and infiltration techniques.

Topical anaesthetic spray and gel have both advantages and disadvantages. The advantages of topical gels include better localization of drug in comparison with ointments and solutions, better control over systemic drug absorption, greater bioavailability and reduction in dosage. However, gels get diluted in the mouth with time, resulting in is difficulty in maintaining prolonged mucosal contact resulting in inadequate anaesthesia.

Topical anaesthetic sprays have greater concentration of local anaesthetic and are absorbed rapidly across the mucous membrane, thus providing effective anaesthesia [6]. Unmetered sprays have potential for systemic toxicity and hence it is recommended that metered spray with disposable nozzles be used.Nummit spray used in this study fulfils this recommendation. The spray contains lignocaine hydrochloride in water-oil based emulsion, which increases tissue penetration and access into the nerve cell [9].

Compound topical anaesthetics increase the risk of systemic toxicity but when used cautiously, with predetermined dosage, can be safe and effective. In our study, pain before, during, and after the IANB procedure between Lidocaine spray and Lox $2 \%$ jelly treatments showed no statistically significant difference, suggesting that the efficacy of both agents in pain reduction was identical throughout the IANB procedure.

In this study, pain assessment was done after injecting the solution which may confound the results. Hence, in needle penetration studies pain assessment is done soon after the needle prick and no solution is injected. However, injection studies have the advantage of the procedure being carried out in a real clinical situation, which makes the results more reliable. Assessment of pain after injection of local anaesthetic may result in higher pain score.

The limitations of the present study were the small sample size, inability to differentiate sex-based responses, and the inclusion of only one type of block anaesthesia (IANB). Future investigations should include clinical trials involving large sample sizes of different age groups with the inclusion of various local anaesthesia administration techniques.

\section{Conclusion}

To conclude, patients experienced less pain during the time of injection prick on application of Lignocaine spray than on application of lidocaine gel. Hence, this study suggests that lignocaine spray may be advantageous in providing anaesthesia during prophylactic extraction, thereby avoiding painful inferior alveolar nerve blocks and preventing local anaesthetic toxicity.

\section{References}

[1]. Hersh EV, Houpt MI, Cooper SA, Feldman RS, Wolff MS, Levin LM. Analgesic efficacy and safety of an intraoral lidocaine patch. J Am Dent Assoc. 1996 Nov;127(11):1626-34; quiz 1665-6. Pubmed PMID: 8952239.

[2]. Carr MP, Horton JE. Evaluation of a transoral delivery system for topical anesthesia. J Am Dent Assoc. 2001 Dec;132(12):1714-9. Pubmed PMID: 11780993.

[3]. Satya Bhushan NV, Nayak RN. A comparison of the efficacy of topical application of Lignocaine Hydrochloride 5\% gel and Bupivacaine Hydrochloride 5\% gel for extraction of teeth. J Maxillofac Oral Surg. 2010 Jun;9(2):11926. Pubmed PMID: 22190770.

[4]. Deepika A, Rao CR, Vinay C, Uloopi KS, Rao VV. Effectiveness of two flavored topical anesthetic agents in reducing injection pain in children: a comparative study. J Clin Pediatr Dent. 2012 Fall;37(1):15-8. Pubmed PMID: 23342561.

[5]. Yamamura K, Yotsuyanagi T, Okamoto T, Nabeshima T. Pain relief of oral ulcer by dibucaine-film. Pain. 1999 Dec;83(3):625-626. Pubmed PMID: 10568871.

[6]. Tulga F, Mutlu Z. Four types of topical anaesthetic agents: evaluation of clinical effectiveness. J Clin Pediatr Dent. 1999 Spring;23(3):217-20. Pubmed PMID: 10686868.

[7]. Malamed SF. Handbook of local anesthesia. Elsevier Health Sciences; 2004 Jun 8.

[8]. American Academy on Pediatric Dentistry Council on Clinical Affairs. Guideline on appropriate use of local anesthesia for pediatric dental patients. Pediatr Dent. 2008-2009;30(7 Suppl):134-9. Pubmed PMID: 19216412.

[9]. Martin MD, Ramsay DS, Whitney C, Fiset L, Weinstein P. Topical anesthesia: differentiating the pharmacological and psychological contributions to efficacy. Anesth Prog. 1994;41(2):40-7. Pubmed PMID: 8638859.

[10]. Pollack S. Pain control by suggestion. J. oral Med.. 1966;21:89-95.

[11]. Meechan JG. Intraoral topical anesthesia. Periodontol 2000. 2008;46:56-79. Pubmed PMID: 18201346.

[12]. Ching D, Finkelman M, Loo CY. Effect of the DentalVibe injection system on pain during local anesthesia injections in adolescent patients. Pediatr Dent. 2014 Jan-Feb;36(1):51-5. Pubmed PMID: 24717710.

[13]. Sharma A, Suprabha BS, Shenoy R, Rao A. Efficacy of lignocaine in gel and spray form during buccal infiltration anesthesia in children: a randomized clinical trial. J Contemp Dent Pract. 2014 Nov 1;15(6):750-4. Pubmed PMID: 25825102.

[14]. Satya Bhushan NV, Nayak RN. A comparison of the efficacy of topical application of Lignocaine Hydrochloride 5\% gel and Bupivacaine Hydrochloride 5\% gel for extraction of teeth. J Maxillofac Oral Surg. 2010 Jun;9(2):11926. Pubmed PMID: 22190770.

[15]. Al-Melh MA, Andersson L. Comparison of topical anesthetics (EMLA/Oraqix vs. benzocaine) on pain experienced during palatal needle injection. Oral Surg Oral Med Oral Pathol Oral Radiol Endod. 2007 May;103(5):e16-20. Pubmed PMID: 17331753.

[16]. van Steenberghe D, Garmyn P, Geers L, Hendrickx E, Maréchal M, Huizar $\mathrm{K}$, et al. Patients' experience of pain and discomfort during instrumentation in the diagnosis and non-surgical treatment of periodontitis. J Periodontol. 2004 Nov;75(11):1465-70. Pubmed PMID: 15633322. 